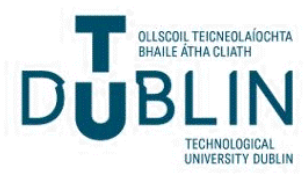

Technological University Dublin

ARROW@TU Dublin

2017-1

\section{Optimization of Atmospheric Air Plasma for Degradation of Organic Dyes in Wastewater}

\author{
Chaitanya Sarangapani \\ Technological University Dublin, chaitanyakrishna.sarangapani@tudublin.ie \\ Yash Dixit \\ Technological University Dublin \\ Vladimir Milosavljevic \\ Technological University Dublin, vladimir.milosavljevic@tudublin.ie
}

See next page for additional authors

Follow this and additional works at: https://arrow.tudublin.ie/schfsehart

Part of the Food Science Commons

\section{Recommended Citation}

Sarangapani, C., Dixit, Y., Milosavljevic, V., Sullivan, C., Bourke, P. \& Cullen, P.J. (2017). Optimization of atmospheric air plasma for degradation of organic dyes in wastewater. Water Science and Technology, 75(1-2), pp. 207-219. doi:10.2166/wst.2016.471

This Article is brought to you for free and open access by the School of Food Science and Environmental Health at ARROW@TU Dublin. It has been accepted for inclusion in Articles by an authorized administrator of ARROW@TU Dublin. For more information, please contact arrow.admin@tudublin.ie, aisling.coyne@tudublin.ie, gerard.connolly@tudublin.ie.

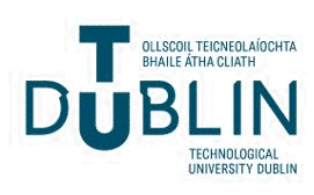


Authors

Chaitanya Sarangapani, Yash Dixit, Vladimir Milosavljevic, Carl Sullivan, Paula Bourke, and Patrick Cullen

This article is available at ARROW@TU Dublin: https://arrow.tudublin.ie/schfsehart/228 


\begin{tabular}{|c|c|}
\hline Manuscript Number: & WST-EM16857R1 \\
\hline Full Title: & Optimization of atmospheric air plasma for degradation of organic dyes in wastewater \\
\hline Short Title: & Degradation of dyes using atmospheric plasma: optimisation study \\
\hline Article Type: & Research Paper \\
\hline Keywords: & Atmospheric air plasma, Methyl orange, bromothymol blue, RSM, R. \\
\hline Corresponding Author: & $\begin{array}{l}\text { chaitanya sarangapani } \\
\text { IRELAND }\end{array}$ \\
\hline \multicolumn{2}{|c|}{$\begin{array}{l}\text { Corresponding Author Secondary } \\
\text { Information: }\end{array}$} \\
\hline \multicolumn{2}{|c|}{ Corresponding Author's Institution: } \\
\hline \multicolumn{2}{|c|}{$\begin{array}{l}\text { Corresponding Author's Secondary } \\
\text { Institution: }\end{array}$} \\
\hline First Author: & chaitanya sarangapani \\
\hline \multicolumn{2}{|c|}{ First Author Secondary Information: } \\
\hline \multirow[t]{5}{*}{ Order of Authors: } & chaitanya sarangapani \\
\hline & yash dixit \\
\hline & paula bourke \\
\hline & carl sullivan \\
\hline & pj cullen \\
\hline \multicolumn{2}{|c|}{ Order of Authors Secondary Information: } \\
\hline Manuscript Region of Origin: & IRELAND \\
\hline Abstract: & $\begin{array}{l}\text { This study optimises the degradation of cocktail of dyes methyl orange and } \\
\text { bromothymol blue by atmospheric air plasma. Response Surface Methodology (RSM) } \\
\text { was employed to investigate the efficacy of the plasma process parameters on } \\
\text { degradation efficiency. A Box Behnken Design (BBD) was employed to optimise the } \\
\text { degradation of dyes by air plasma discharge. A second order polynomial equation was } \\
\text { proposed to predict process efficiency using statistical software R. It was observed that } \\
\text { the predicted values are significant ( } p<0.001 \text { ) with coefficients of determination } 0.98 \text {, } \\
0.96,0.98 \text { for dye degradation, pH value and ozone concentration respectively. The } \\
\text { ANOVA results showed that the coefficients of the polynomials for the percentage } \\
\text { degradation and ozone concentration responses indicated positive linear effects } \\
\text { ( } p<0.001) \text { whereas a negative linear effect was found for pH. The positive linear effect } \\
\text { of variable emphasises that voltage and treatment time were the most dominant factors } \\
(p<0.001) \text { meaning that higher degradation efficiencies are achieved with increases in } \\
\text { treatment duration. This study showed that a BBD model and response surface } \\
\text { methodology could be employed to optimize the colour degradation parameters of non- } \\
\text { thermal plasma treated model dyes while minimising the number of experiments } \\
\text { required. }\end{array}$ \\
\hline
\end{tabular}




\section{Optimization of atmospheric air plasma for degradation of organic dyes in wastewater}

2 Chaitanya Sarangapani ${ }^{1}$, Y. Dixit ${ }^{1}$, Vladimir Milosavljevic, Paula Bourke ${ }^{1}$, Carl Sullivan ${ }^{1}$, P.J.

3 Cullen ${ }^{1,2}$

$4 \quad{ }^{1}$ BioPlasma Research Group, Dublin Institute of Technology, Dublin 1, Ireland

$5 \quad{ }^{2}$ School of Chemical Engineering, University of New South Wales, Sydney, Australia.

$6 \quad *$ Corresponding Author ( $\square$ ): P.J. Cullen; Tel (沺): +353 1402 7595; E-Mail: pjcullen@dit.ie

7

8

9

10

11

12

13

14

15

16

17

18 
Abstract:

20 This study optimises the degradation of cocktail of dyes methyl orange and bromothymol blue by 21 atmospheric air plasma. Response Surface Methodology (RSM) was employed to investigate the 22 efficacy of the plasma process parameters on degradation efficiency. A Box Behnken Design 23 (BBD) was employed to optimise the degradation of dyes by air plasma discharge. A second 24 order polynomial equation was proposed to predict process efficiency. It was observed that the 25 predicted values are significant $(p<0.001)$ with coefficients of determination $0.98,0.96,0.98$ for 26 dye degradation, $\mathrm{pH}$ value and ozone concentration respectively. The ANOVA results showed 27 that the coefficients of the polynomials for the percentage degradation and ozone concentration 28 responses indicated positive linear effects $(p<0.001)$ whereas a negative linear effect was found 29 for $\mathrm{pH}$. The positive linear effect of variable emphasises that voltage and treatment time were the 30 most dominant factors $(p<0.001)$ meaning that higher degradation efficiencies are achieved with 31 increase in treatment duration. This study showed that a BBD model and response surface 32 methodology could be employed to optimize the colour degradation parameters of non-thermal 33 plasma treated model dyes while minimising the number of experiments required.

34 Keywords: Atmospheric air plasma, Methyl orange, bromothymol blue, RSM. 


\section{Introduction:}

Atmospheric air cold plasma is an emerging advanced oxidation process (AOP) for the treatment of organic contaminants. Such plasma discharges have recently been proposed for medical applications such as sterilization, bio-decontamination, surface modification and for environmental applications such as air pollution and as surface engineering tool (Machala et al. 2007; Sarangapani et al. 2016b). In a recent study, Jiang et al.,(2014) reviewed the application of non-thermal or cold plasma for the treatment of waste water. The unique and highly active chemistry associated with atmospheric plasmas offer significant potential for the degradation of contaminants in water and wastewater (Mok et al. 2008). Dielectric Barrier Discharge (DBD) plasma discharges initiates several physical processes viz., UV light, shock waves and chemical processes viz, $\cdot \mathrm{OH}, \cdot \mathrm{O}, \cdot \mathrm{H}$, radicals, ozone and hydrogen peroxide which directly or indirectly lead to the degradation of organic compounds (Sarangapani et al. 2015; Thirumdas et al. 2015). In addition to this, positive and negative ions, excited species, excited neutral molecules are also generated. The mechanism of degradation initiates with the formation of high energy electrons in the discharge (Rohit Thirumdas 2016). These high energy electrons react with gas and water molecules to produce reactive species like $\cdot \mathrm{O} \cdot \mathrm{H}, \cdot \mathrm{OH}, \mathrm{O}_{3}$ (Feng et al. 2008). Metastables such as ozone are highly soluble in water and forms ${ }^{\circ} \mathrm{OH}$ (Wei et al. 2014), however the efficacy of UV radiation is found to be reduced in the presence of $\mathrm{O}_{3}$. A number of studies have demonstrated the successful degradation of organic dyes using DBDs. Reports on the degradation of azo dyes include methylene blue (Reddy et al. 2013) and methyl orange (Grabowski et al. 2007) degradation. Non-thermal plasma technology in combination with modified activated carbon fibers was also used for the degradation of organic dyes (Jiang et al. 2013). It has been observed from previous study (Misra et al. 2015) that the efficiency of non-thermal dye degradation is 
62 dependent on various parameters such as applied voltage, treatment time, initial dye 63 concentration, $\mathrm{pH}$ and ozone. In order to study a process, conventional methods and classical 64 methods were used. In this methods, the influence of each of these parameters were carried out 65 by varying studied parameters while keeping others constant (Kasiri et al. 2013). These methods 66 are also time consuming, requires a number of experiments to determine optimum levels, which 67 are unreliable. Moreover, these methods do not depict the combined effect of all parameters 68 involved. These limitations can be eliminated by optimizing all the affecting parameters 69 collectively by statistical experimental design such as response surface methodology (RSM) 70 (Ravikumar et al. 2007). RSM is a collection of mathematical and statistical techniques useful 71 for developing, improving and optimizing the processes. This is technique can also estimate 72 linear, interaction, and quadratic effects of the factors and provides a prediction model for the 73 response. In fact, this can also be used to evaluate the relative significance of several affecting 74 factors even in the presence of complex interactions with minimum number of 75 experiments.(Ravikumar et al. 2007). Hence, this method can be applied for optimizing the 76 atmospheric plasma process parameters for degradation of dyes. Few reports on use of RSM in 77 optimization of decolorisation process by advanced oxidation processes include comparable 78 studies on optimization using RSM include the degradation of azo dyes by ozonation 79 (Muthukumar et al. 2004; Kasiri et al. 2013) and the degradation of Reactive Green 19 (RG19) 80 by the $\mathrm{UV} / \mathrm{H}_{2} \mathrm{O}_{2}$ treatment(Zuorro et al. 2013). Such approaches help minimise the number of 81 experiments required for process optimisation. Also, to facilitate industrial adoption of this 82 technology an improved understanding of treatment efficiency and the efficacy of plasma 83 process parameters optimization on the degradation of dyes is required. Moreover, to the best of 
84 our knowledge there are no studies on the optimization of non-thermal process parameters for the 85 degradation process as an emerging Advanced oxidation process (AOP).

86 In this study, modelling and optimization of dye degradation for a cocktail of analytical 87 grade methyl orange and bromothymol blue was performed by employing box-behnken design 88 with RSM methodology. The study employs the use of a high voltage, large gap DBD plasma 89 with atmospheric air as the inducer gas, which has recently shown significantly higher efficacies 90 for dye degradation (Misra et al. 2015), pesticide degradation (Moiseev et al. 2014) and 91 microbial inactivation (Patil et al. 2014) than studies previously reported at lower voltages. 92 Given the low energy input and use of atmospheric air, the process has potential for large scale 93 waste water treatment applications. The influencing factors (variables) employed were voltage, 94 treatment time and dye concentration. Responses monitored were the degradation efficiency, 95 ozone concentration and $\mathrm{pH}$.

96 2. Materials and Methods:

97 2.1. Materials

\section{$98 \quad 2.1 .1$ Reagents and selection of dye concentration}

99 Analytical-grade methyl orange and bromothymol blue dyes were obtained (Sigma-Aldrich, 100 Ireland). Concentrations of these dyes were prepared by serial dilution to a final concentration 101 within the maximum absorption range of the UV-Vis spectrophotometer (Shimadzu UV 1800, 102 Shimadzu Scientific Instruments). Based on the spectral data of the dilutions, a cocktail of the 103 three dye standards was prepared in water at $50 \mathrm{mg} / \mathrm{L}, 75 \mathrm{mg} / \mathrm{L}$ and $100 \mathrm{mg} / \mathrm{L}$ concentration each 


\subsubsection{Atmospheric air plasma treatment:}

105 The experimental set-up employed for this work is shown in Fig 1. The apparatus consists of two 106 aluminium plate electrodes of circular geometry (outer diameter $=158 \mathrm{~mm}$ ) which are covered with dielectric materials of $2 \mathrm{~mm}$ thickness for ground electrode and 10mm thick perspex for high voltage electrode. In between the two dielectrics recide a removable polypropylene (PP) reactor of dimensions $310 \mathrm{~mm} \times 230 \mathrm{~mm} \times 22 \mathrm{~mm}$. Each reactor holds a petri plate with $10 \mathrm{ml}$ dye placed directly between the electrodes. The reactor acts as a closed chamber holding the reactive species generated and as an additional dielectric. In order to prevent loss of the reactive species generated during and after treatment, the PP containers with petri plate were sealed inside a high barrier Cryovac BB3050 film. An additional layer of PP board was placed at the ground electrode in order to prevent arcing and distribute the discharge uniformly. Atmospheric air was used as a working gas. The top electrode was connected to a high voltage step-up transformer (Phenix Technologies, Inc., USA) where the primary winding receives input at 230 $\mathrm{V}, 50 \mathrm{~Hz}$ and delivers a high voltage output in the range $0-120 \mathrm{kV}$ RMS. Plasma treatment was performed at different voltages $(30-80 \mathrm{kV})$ and treatment times (30-180 seconds). Treatment of all dye samples was carried out in duplicate and at ambient temperature $\left(16-18{ }^{\circ} \mathrm{C}\right)$. All sealed containers were then kept at room temperature of $16-18^{\circ} \mathrm{C}$ for a post treatment storage time of 24 $\mathrm{h}$ to ensure contact with longer lived species.

\subsection{Experimental design and Data analysis:}

The effect of the three independent process parameters; voltage $\mathrm{X}_{1}(\mathrm{kV})$, treatment time $\mathrm{X}_{2}(\mathrm{sec})$ and dye concentration $\mathrm{X}_{3}(\mathrm{mg} / \mathrm{L})$ on the dependent variable were studied using response surface methodology. A box-behnken design was employed, and coded as -1, 0, 1 with the ranges determined via preliminary studies. The independent variables were $\mathrm{X}_{1}\left(30-70 \mathrm{k} \mathrm{V}_{\mathrm{RMS}}\right), \mathrm{X}_{2}(30$ - 


\subsection{Electrical characterisation of discharge}

Electrical characterisation of the discharge was performed using an Agilent InfiniVision 2000 XSeries Oscilloscope (Agilent Technologies Inc., USA). The voltage across the electrode was recorded using a high voltage North Star PVM-6 probe together with a 10:1 voltage divider. The current waveform was measured using a current transformer probe (Bergoz CT-E1.0S).

\subsection{Ozone measurement}

Ozone concentrations generated within the reactor were taken as a measure of one of the meta stable oxygen species generated and measured using short-term ozone detection tubes obtained from Gastec (Product No. 18M, Gastec, Japan). These tubes contain a reagent which changes its colour upon contact with the specified gas and are calibrated for specific sampling volumes. 
149 Ozone concentrations were measured immediately following each treatment. Further details

150 regarding gas measurement methodology can be found elsewhere (Misra et al. 2014).

\section{5 . Optical emission spectroscopy}

152 Spectra of the discharge emissions were acquired with a computer controlled Ocean Optics 153 spectrometer (HR2000+), to which the light from the plasma is coupled via an optical fibre (Fig 154 1). The fibre had a numerical aperture of 0.22 and is optimised for use in the ultraviolet and 155 visible portion of the spectrum. The $\mathrm{HC} 1$ variable blaze diffraction grating coupled with a $25 \mu \mathrm{m}$ 156 slit allows for a wavelength resolution of $1.1 \mathrm{~nm}$. The spectrometer operates in the wavelength 157 range of $200 \mathrm{~nm}$ to $1050 \mathrm{~nm}$. Emission spectra and corresponding noise spectra were recorded 158 using integration times of $5000 \mathrm{~ms}$ and averaged over 10 measurements. Spectra were recorded 159 with and without dye samples in the reactor during the discharge. All spectra were corrected for 160 noise levels by subtracting the background noise.

\subsection{Absorption spectra of dyes}

162 The dye samples were sampled into $1 \mathrm{~cm}$ path length cuvettes and their visible absorption 163 spectra were obtained using a spectrophotometer (Shimadzu UV 1800, Shimadzu Scientific 164 Instruments). Degradation efficiency was defined as the percentage decrease of absorbance 165 according to the following equation

$$
\text { Degradation }[\%]=\frac{A_{0}-A}{A_{0}} \times 100
$$

166 Where $A_{0}$ is the absorbance of untreated dye solution ( 0 s treatment) and $A$ is the absorbance at 167 time ' $t$ ' at wavelength of maximum absorption $\left(\lambda_{\max }\right)$. 
168 A first-order kinetics model was evaluated for modelling the experimental data for dye 169 degradation. The first-order model is given by equation 3:

$$
A_{t}=A_{\max }-A_{\max } e^{-k t}, A_{\max } \leq 100
$$

170 Where, $A_{t}$ is the $\%$ degradation at any time, $t(\mathrm{~s}), A_{\max }$ is the maximum degradation, $k$ is the 171 rate constant $\left(\mathrm{s}^{-1}\right)$

\section{$172 \quad 2.7$. Measurement of $\mathrm{pH}$}

173 The $\mathrm{pH}$ of all dye samples were measured after $24 \mathrm{~h}$ storage using a calibrated glass electrode 174 ORION pH meter (model 420A, Thermo Fisher Scientific Inc.) at ambient temperature $\left(16^{\circ} \mathrm{C}\right)$.

\section{3. Results and discussion:}

176 3.1. Preliminary analysis of dye degradation:

177 The absorption spectrum of the dyes is shown in Fig 2. The maximum absorption was observed 178 in the visible region $\left(\lambda_{\max }=616 \mathrm{~nm}\right)$. The degradation process was investigated by observing the 179 respective spectral changes. However, it was observed that a decline in the intensities at two 180 wavelengths, in the UV $\left(\lambda_{\max }=308 \mathrm{~nm}\right)$ and visible $\left(\lambda_{\max }=616,624 \mathrm{~nm}\right)$ regions were associated 181 with an increase in the treatment time. The decrease in intensities was due to degradation and 182 dearomatization of organic dye by plasma excited and reactive species $\mathrm{O}^{*}, \mathrm{OH}, \mathrm{N}^{*}, \mathrm{HO}_{2}^{*}, \mathrm{~N}_{2}{ }^{*}$, $183 \mathrm{~N}^{*}, \mathrm{OH}^{-}, \mathrm{O}_{2}^{-}, \mathrm{O}^{-}, \mathrm{O}_{2}^{+}, \mathrm{N}_{2}^{+}, \mathrm{N}^{+}$, and $\mathrm{O}^{+}($Dojčinović et al. 2011). Fi.2. shows the absorbance 184 changes at $616 \mathrm{~nm}$ as a function of time for a treatment at voltage $40 \mathrm{kV}$. The $\%$ degradation 185 increased with treatment time and the degradation process followed first-order kinetics with the 186 rate constant increasing with treatment time. The results obtained from preliminary analysis 187 concluded that increase in treatment time increases degradation efficiency. The increase in 
188 plasma input parameters of voltage increases the generation of reactive species such as ozone, 189 hydroxyl radicals, and hydrogen peroxide.

190 3.2. Current-Voltage characteristic of plasma source:

191 The typical waveforms found for the discharge at different voltages are shown in Fig. 3. A stable 192 non-thermal discharge was seen at large gaps of $2.3 \mathrm{~cm}$. The observations deduced that the 193 applied voltage was sinusoidal and the total current in the dielectric barrier discharge consists of 194 filamentary streamers which may trigger photo ionization. The dielectric material plays a key 195 role in the operation by limiting the charge and preventing arcing (Dojčinović et al. 2011). 196 Further details regarding electrical characteristics of the discharge using capacitance-voltage 197 Lissajous patterns can be found in a recent publication by (Moiseev et al. 2014).

198 3.3. Optical Emission Spectroscopy (OES) of plasma:

199 The energy transferred to the plasma causes excitation of the air molecules. Optical emission 200 spectroscopy was employed to identify the chemical species formed by the plasma. The spectrum 201 of radiations emitted was grated and OES intensities were measured as a function of wavelength. 202 The emission spectrum obtained in the wavelength range of $180-900 \mathrm{~nm}$ for atmospheric air 203 plasma at 50 and $70 \mathrm{kV}$ with and without samples are shown in Fig.4. The emissions were 204 stronger for the empty containers than those containing samples; which was due to the influence 205 of the samples on the discharge area. The spectral reading was recorded within a few seconds of 206 plasma initiation.

207 It is evident from the emission spectrum $(300-400 \mathrm{~nm})$ that the DBD operating in atmospheric air 208 is a weak source of UV, which is in agreement with the previous studies conducted by (Heise $e t$ 209 al. 2004). The distinct peaks observed in the UV region are emissions from $\mathrm{N}_{2}$ and excited 
211 low emissions of $\mathrm{O}$ were also noted between 780 and $840 \mathrm{~nm}$ (Laux et al. 2003). The lower

212 intensities of these emissions were expected in the air plasmas due to quenching of $\mathrm{O}\left({ }^{3} \mathrm{P}\right)$ and $\mathrm{O}$ $213\left({ }^{5} \mathrm{P}\right)$ (Walsh et al. (2010). It could be inferred from the spectra, that the atmospheric air plasma 214 employed is a source of reactive oxygen and nitrogen species (ROS \& RNS).

\section{3.4. Second order polynomial model}

216 In this experiment, a box behnken design was used to form a mathematical model for the 217 degradation process behaviour. The experiments were performed according to the design, factors 218 and the selected levels. The coefficients of the mathematical model were estimated to predict the 219 response and finally, the adequacy of the generated model was determined. The box behnken 220 design (BBD) matrix showing coded and actual level of variables are presented in Table 2 . The 221 experimental and predicted results of the response functions (\% degradation, $\mathrm{pH}$ value and ozone 222 concentration) are presented in Table 3.

223 The second order polynomial (equation 1) was used to correlate the dependent and 224 independent variables. The value of the coefficients was estimated using ANOVA (Table 4) and 225 the second-order equation used for predicting the response functions (\% degradation, $\mathrm{pH}$ value 226 and ozone concentration) for methyl orange dye is expressed as follows (equations 4-6):

$$
\begin{aligned}
& (\% \text { degradation }) Y=91.674+6.289 x_{1}+5.400 x_{2}-0.685 x_{3}-2.852 x_{1} x_{2} \\
& -0.019 x_{1} x_{3}+0.096 x_{2} x_{3}+1.531 x_{1}^{2}-1.675 x_{2}^{2}-0.947 x_{3}^{2} \\
& (p \text { Hvalue }) Y=2.757-0.090 x_{1}-0.100 x_{2}+0.020 x_{3}-0.01 x_{(1)} x_{2}-1.138 \times 10^{-16} x_{1} x_{3} \\
& +0.015 x_{2} x_{3}+0.064 x_{1}^{2}-0.083 \times 10^{-2} x_{2}^{2}-0.004 x_{3}^{2}
\end{aligned}
$$




$$
\begin{aligned}
& \text { (Ozoneconc. }) Y=1650+525 x_{1}+506.250 x_{2}-31.250 x_{3}+125 x_{1} x_{2}+25 x_{1} x_{3} \\
& -62.500 x_{2} x_{3}-231.250 x_{1}^{2}-93.750 x_{2}^{2}+156.25 x_{3}^{2}
\end{aligned}
$$

227 The response functions viz. \% degradation, $\mathrm{pH}$ value and ozone concentration were predicted by 228 equations 4,5 and 6 respectively and the values are shown in Table 4.

229 3.5. Model validation

230 Fig.5. shows the predicted values of the response functions; \% degradation, $\mathrm{pH}$ value and ozone 231 concentration. The coefficient of determination $\left(R^{2}\right)$ shows the accuracy of the predicted models. 232 It is evident from Fig.6., that the models were able to predict the response functions with high 233 accuracy indicated by high $R^{2}$ values of $0.98,0.96$, and 0.98 for $\%$ degradation, $\mathrm{pH}$ value and 234 ozone concentration respectively. The model explains about $98 \%, 96 \%$, and $98 \%$ variability of 235 the response functions; \% degradation, $\mathrm{pH}$ value and ozone concentration respectively.

\section{6} 237

\subsection{Fitting the quadratic model using Analysis of variance}

Analysis of variance (ANOVA) was used to test the significance and capability of the model.

The results of the quadratic response surface model fitting in the form of analysis of variance are shown in Table 4. The proposed models predicted the performance of the plasma process on the basis of following response functions; \% degradation, $\mathrm{pH}$ value and ozone concentration with high accuracy as evident from the $R^{2}$ values. Adjusted $R^{2}$ is a better measure of the goodness of fit as compared to $R^{2}$ for comparing models with different numbers of independent variables (Kasiri et al. 2013). In the present study, adjusted $R^{2}$ values and the corresponding $R^{2}$ values were close to each other as shown in Table 4. 
The $\mathrm{F}$ ratio is the ratio between the mean square of the model and the residual error. It shows whether the model is significant or not when compared to their respective residual errors.

247 If the $F$ value is greater than the tabulated value of the $F$ distribution for a certain number of 248 degrees of freedom in the model at the level of significance $\alpha$, then the model is a good predictor 249 of the experimental results (Kasiri et al. 2013). The $F$ values for $\%$ degradation, $\mathrm{pH}$ value and 250 ozone concentration were $27.21,12.25$, and 29.52 respectively, which were greater than the 251 tabulated $F$ values (4.772 at 95\% significance) confirming the adequacy of the model fits.

\section{3.7. Analysis of box behnken design results using surface and contour plots}

253 The Student's $t$ test determines the significance of the regression coefficient of the parameters. 254 The $P$ values also check the significance of each of the coefficients and are necessary to 255 understand the mutual interactions between the test variables (Kasiri et al. 2013). The surface 256 plots were generated keeping one variable constant at their zero level and the other two variables 257 varied within their experimental range. These plots represent the linear as well as quadratic 258 effects of the individual variables.

259 The coefficients of polynomials relating to the \% degradation of the dye indicate that the 260 linear effects of the variables were prominent except for the dye concentration (Table 4). 261 Applied voltage had the strongest positive linear effect (Fig. 6 a, b) which was followed by the 262 treatment time (Fig. 6 b, c). The \% degradation observed was maximum at the highest voltage 263 and longest treatment duration. The quadratic effects of these variables were usually non264 significant (at $p=0.10$ ) except for the interaction effect of voltage and treatment time which was 265 significant (at $p \leq 0.05$ ) and produces a negative effect. This means that the effect of voltage on 266 the \% degradation depends on the duration of treatment time. This phenomenon produces a 267 curvilinear effect on the \% degradation (Fig.6. a). If the experiments were conducted by 
268 conventional methods, the significance of quadratic and interaction effects between variables would have been lost. Chemically, the degradation of the dye was due to cleavage of the azo groups $(-\mathrm{N}=\mathrm{N}-)$ which are responsible for the characteristic colour of the dye. Irreversible discoloration of the dye was due to oxidative species in a particular ozone and hydroxyl radicals which break the aromatic and other molecules containing $-\mathrm{C}=\mathrm{C}-$ and $-\mathrm{N}=\mathrm{N}$ - bonds. Oxidation 273 takes place either due to direct or indirect oxidative reactions by converting to hydroxyl radical 274 (Huang et al. 2010).

275 Error! Reference source not found. shows the coefficients of polynomials for $\mathrm{pH}$ values, where it 276 was observed that the negative linear effect of treatment time was the most dominant factor (Fig. $277 \mathbf{a}$ a, c) which means that an increase in the treatment time increases the acidity of dye. The shift 278 in $\mathrm{pH}$ values in the dye samples after plasma treatment may be due to the formation of strong 279 acids like nitric acid $\left(\mathrm{HNO}_{3}\right)$ and nitrous acid $\left(\mathrm{HNO}_{2}\right)$ as well as due to hydrogen peroxide $280\left(\mathrm{H}_{2} \mathrm{O}_{2}\right)$ (Oehmigen et al. 2010). Diffusion of active species into the solution with oxidation of the 281 dyes was responsible for the acid formation. The next factor of importance was voltage which 282 also had a negative linear effect on $\mathrm{pH}(p \leq 0.01)$. The quadratic effect of voltage alone was 283 significant (at $p \leq 0.05$ ), which produces a curvilinear effect on $\mathrm{pH}$ (Fig.7.a, b). The quadratic 284 effect of the other variables was non-significant.

$$
\begin{gathered}
\mathrm{N}_{2}+e^{-} \rightarrow 2 \mathrm{~N}^{\cdot}+e^{-} \\
\mathrm{O}_{2}+e^{-} \rightarrow 2 \mathrm{O}+e^{-} \\
\mathrm{N}^{\cdot}+\mathrm{O}^{\cdot} \rightarrow \mathrm{NO}_{2}
\end{gathered}
$$




$$
\begin{gathered}
\mathrm{NO}_{2}^{-}+\mathrm{H}_{2} \mathrm{O}_{2}+\mathrm{H}_{3} \mathrm{O}^{+} \rightarrow \mathrm{ONOOH}+2 \mathrm{H}_{2} \mathrm{O} \\
\mathrm{ONOOH}+2 \mathrm{H}_{2} \mathrm{O} \leftrightarrow \mathrm{ONOO}^{-}+\mathrm{H}_{3} \mathrm{O}^{+} \\
\mathrm{NO}_{2}+\mathrm{OH} \rightarrow \mathrm{HNO}_{3}
\end{gathered}
$$

285 The coefficients of polynomials (Table 4) indicate that the linear effects of the variables 286 related to the ozone concentration were prominent. Among all three variables, voltage had the 287 strongest positive linear effect (Fig. 8. a, b) which was followed by the positive linear effect due 288 to treatment time (Fig. 8. a, c). However, the effect due to dye concentration was non-significant. 289 High dye concentration logically enhances the probability of collision between organic matter 290 and oxidizing species, leading to a decrease in the discoloration rate. The quadratic effects of 291 these variables were non-significant except for voltage alone (significant at $p \leq 0.05$ ). It produces 292 a curvilinear effect on ozone concentration (Fig. 8 a, b). The following mechanism explains the 293 formation of ozone equations 13-15.

$$
\begin{gathered}
e+\mathrm{O}_{2} \rightarrow \mathrm{O}+\mathrm{O}+e \\
\mathrm{O}+\mathrm{O}_{2} \rightarrow \mathrm{O}_{3} \\
3 \mathrm{O}_{3}+\mathrm{H}_{2} \mathrm{O} \rightarrow 2 . \mathrm{OH}+4 \mathrm{O}_{2}
\end{gathered}
$$

294 Dielectric barrier discharge (DBD) is one of the most efficient methods to produce ozone 295 (Amjad et al. 2012). Ozone which is produced in DBD acts as a powerful oxidant with a redox 296 potential of 2.07 which is also chemically stable (Tizaoui \& Grima 2011). Using high voltage 297 permits an increased number of collisions with oxygen to form ozone. Ozone mechanism of 298 degradation proceeds in two stages, firstly molecular interactions through electrophillic attack on 
299 bonds such as $-\mathrm{N}=\mathrm{N}-$ azo chromophoric groups, double bonds of $-\mathrm{C}=\mathrm{C}-$ connecting aromatic groups. Secondly, oxidation of dye is subject to direct reaction with compounds such as - $-\mathrm{OH},-$

302 Maciejewska et al. 2000). Several authors have reported the mechanism of degradation by ozone 303 takes place indirectly at high $\mathrm{pH}$, while in acidic environments direct reaction is predominant 304 (Misra et al. 2015; Sarangapani et al. 2016a). At low pH a slow reaction takes place between the 305 dissolved ozone and hydrogen peroxide which result in the formation of hydroxyl radicals, but 306 these reactions are greatly accelerated at high $\mathrm{pH}$. Thus, ozone, hydroxyl radicals, hydrogen 307 peroxide are considered as the principal active species responsible for the degradation of dyes 308 (see equations16-23). Besides ozone, electrical discharges in humid air also produce a variety of 309 excited and active species, such as $\mathrm{O}^{\bullet},{ }^{\bullet} \mathrm{OH}, \mathrm{N}^{\bullet}, \mathrm{HO}_{2}{ }^{\bullet}, \mathrm{N}_{2}{ }^{*}, \mathrm{~N}^{*}, \mathrm{OH}^{-}, \mathrm{O}_{2}^{-}, \mathrm{O}^{-}, \mathrm{O}_{2}{ }^{+}, \mathrm{N}_{2}^{+}, \mathrm{N}^{+}$, and $310 \mathrm{O}^{+}$(Dojčinović et al. 2011). Ozone and other active species produced in the gas phase 311 subsequently gets dissolved in the aqueous phase and reacts with the dye. For a detailed 312 computational analysis of the principal meta stable species generated with this DBD ACP system 313 the reader is directed to (Moiseev et al. 2014).

$$
\begin{gathered}
\mathrm{H}_{2} \mathrm{O}+e^{-} \rightarrow \mathrm{H}^{\cdot}+\mathrm{OH}^{\cdot}+e^{-} \\
\mathrm{O}+\mathrm{O}_{2} \rightarrow \mathrm{O}_{3} \\
\mathrm{H}_{2} \mathrm{O}+e^{-} \rightarrow \mathrm{H}^{\cdot}+\mathrm{OH}^{\cdot}+e^{-} \\
\mathrm{O}_{3}+\mathrm{OH} \rightarrow \cdot \mathrm{HO}_{2}+\mathrm{O}_{2} \\
\mathrm{OH} \cdot+\mathrm{OH} \cdot \rightarrow \mathrm{H}_{2} \mathrm{O}_{2}
\end{gathered}
$$




$$
\begin{gathered}
\mathrm{H}^{\cdot}+\mathrm{O}_{2} \rightarrow \mathrm{HO}_{2} \\
\mathrm{HO}_{2}^{\cdot}+\mathrm{H}^{\cdot} \rightarrow \mathrm{H}_{2} \mathrm{O}_{2} \\
\mathrm{H}_{2} \mathrm{O}_{2}+\mathrm{O}_{3} \rightarrow . \mathrm{OH}+\mathrm{O}_{2}+. \mathrm{HO}_{2}
\end{gathered}
$$

The results from ANOVA suggests that second order polynomials can adequately explain all three response functions. Further, among the independent variables, the voltage has the most dominant positive linear effect on the \% degradation and ozone concentration. However, it had a negative linear effect on $\mathrm{pH}$. The second most dominating effect was treatment time which also possesses similar effects on all three response functions as voltage. However, dye concentration does not seem to have any effect on the response functions. All the independent variables except dye concentration mostly offer a linear effect while their quadratic and interaction effects were marginal. A high coefficient of determination $\left(R^{2}=0.98, p \leq 0.001\right),\left(R^{2}=0.96, p \leq 0.01\right)$ and $\left(R^{2}=\right.$ $0.98, p \leq 0.001)$ indicates the suitability of the second order polynomial for the $\%$ degradation, $\mathrm{pH}$ 323 value and ozone concentration respectively. The accuracy of the predicted models was 324 determined by performing paired t-test among experimental and predicted values. The optimized 325 conditions of plasma process parameters for maximum degradation and ozone concentrations 326 were found to be $70 \mathrm{kV}$ voltage, 120 s treatment time and $100 \mathrm{mg} / \mathrm{L}$ dye concentration. The results 327 of paired t-test showed that the values were not significant at $p<0.05$ and predicted values were 328 within range of experimental values.

\section{3.8. Conclusion}

330 It can be concluded that response surface methodology (RSM) using box-behnken (BBD) design 331 is an effective technique to investigate colour degradation for the cocktail of dyes as a function 332 of the plasma process parameters. RSM could effectively predict and optimise the plasma 
333 process. Results from analysis of variance showed high coefficient of determination values $334\left(R^{2}>0.95\right)$ for the three responses ensuring a satisfactory adjustment of the second-order 335 polynomial model with the experimental data. The significant influence either independently or 336 interactively, on degradation by the three independent variables were clearly described through 337 response surface plots. Plasma process parameters; treatment time and voltage were found to be 338 most significant factors for degradation. The findings in particular demonstrate the potential 339 impact of employing very high voltages $(>70 \mathrm{kV})$ on the degradation efficacy of air plasmas for 340 wastewater treatment. This study improved understanding of the effect of plasma on degradation 341 of colour which is one of the critical parameters of wastewater. However, these results indicate 342 the feasibility of atmospheric air plasma as an emerging technology for industrial adoption.

343 Acknowledgement:

344 The authors would like to acknowledge funding from the Food Institutional Research Measure 345 administered by the Department of Agriculture, Food \& the Marine, Ireland 
$358 \quad$ Figures

359

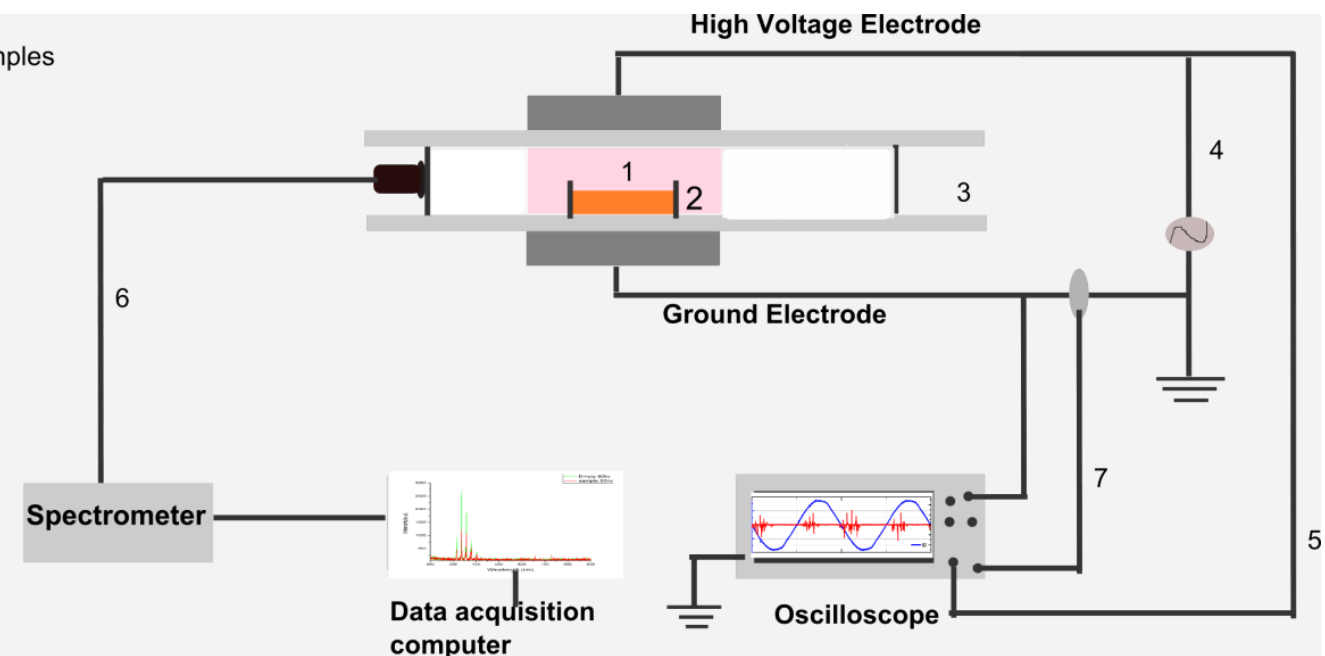

Fig.1. Schematic of the experimental setup with electrical and optical diagnostics 


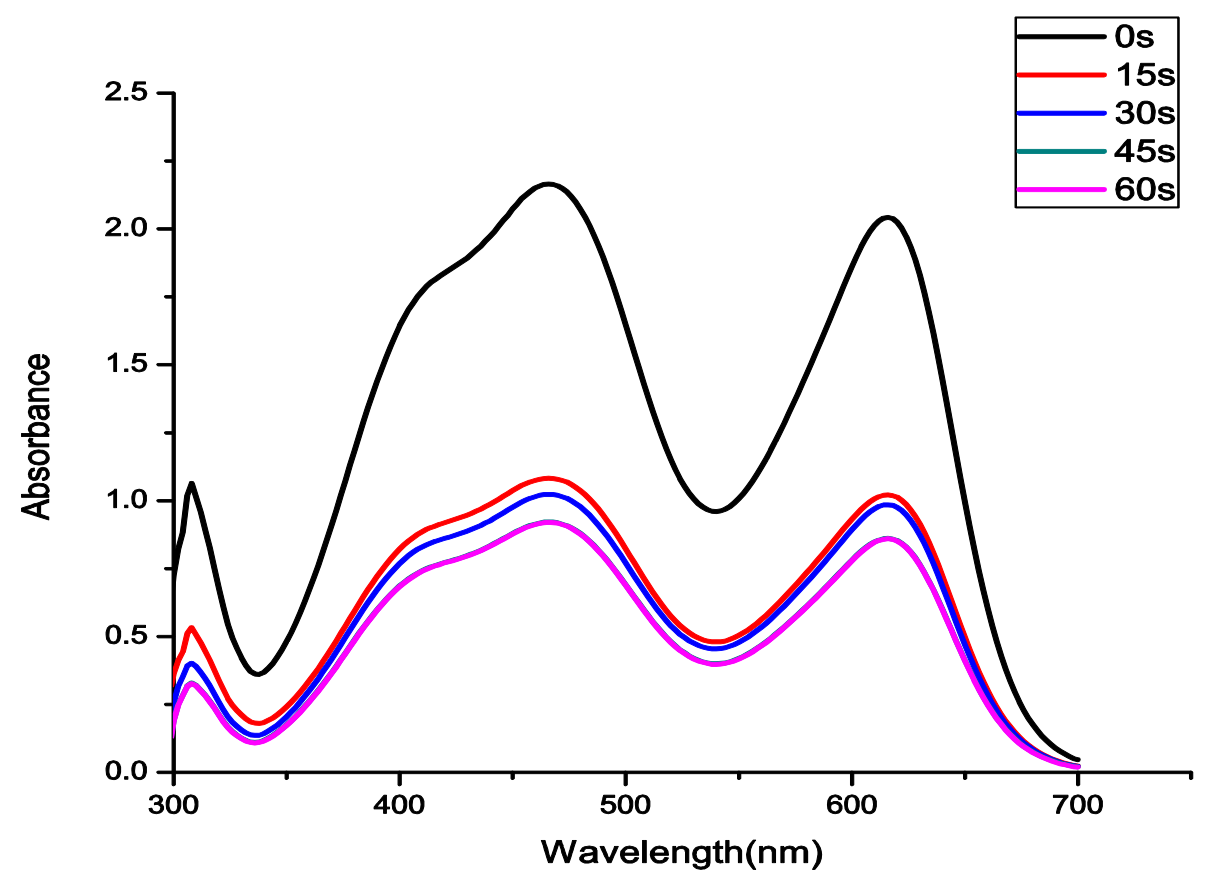

365 Fig.2. Absorption spectra of dye mixture treated directly at 40kVRMS across the electrodes, 

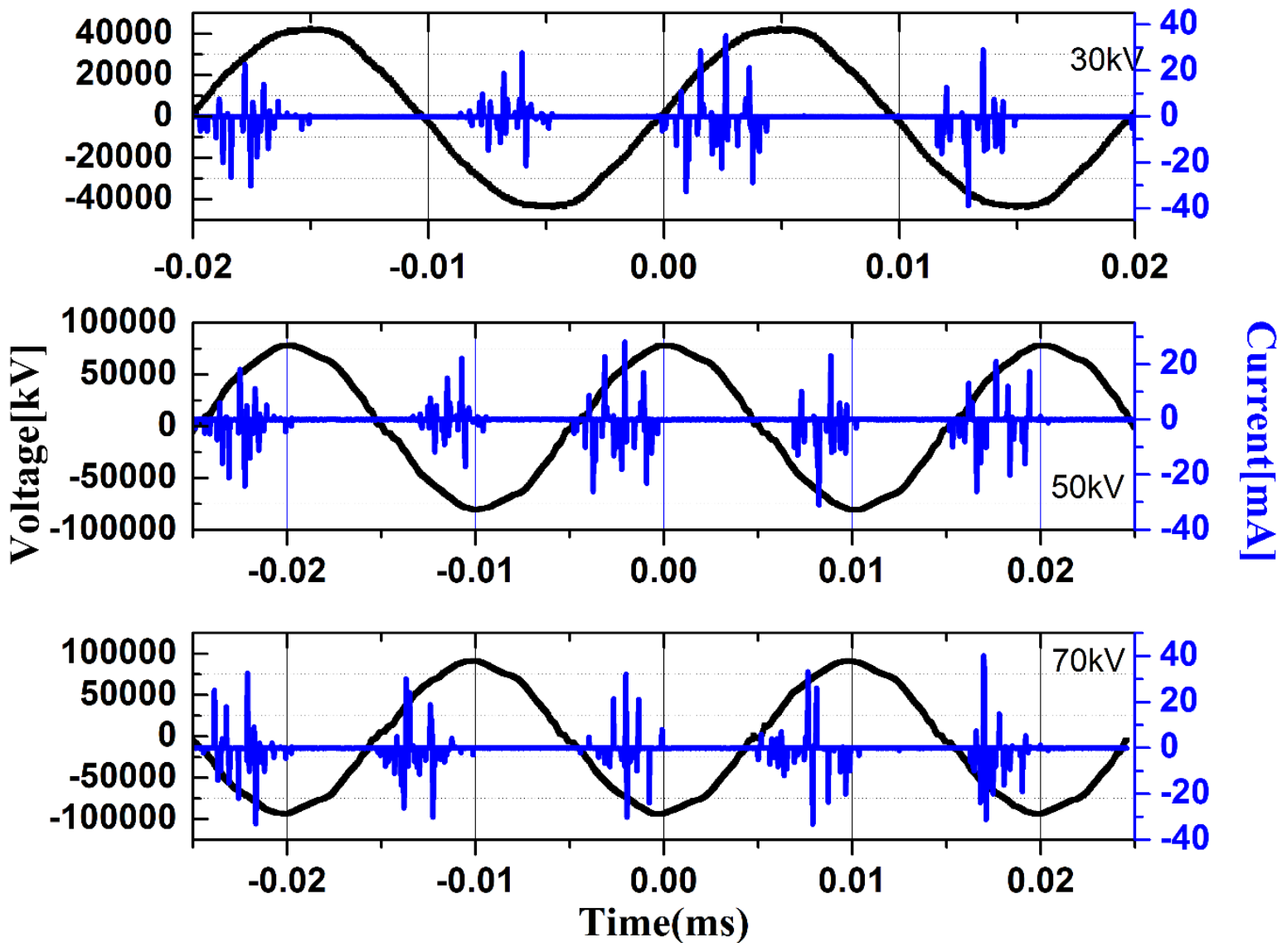

Fig.3. Representative I-V waveforms of the discharge in packages 


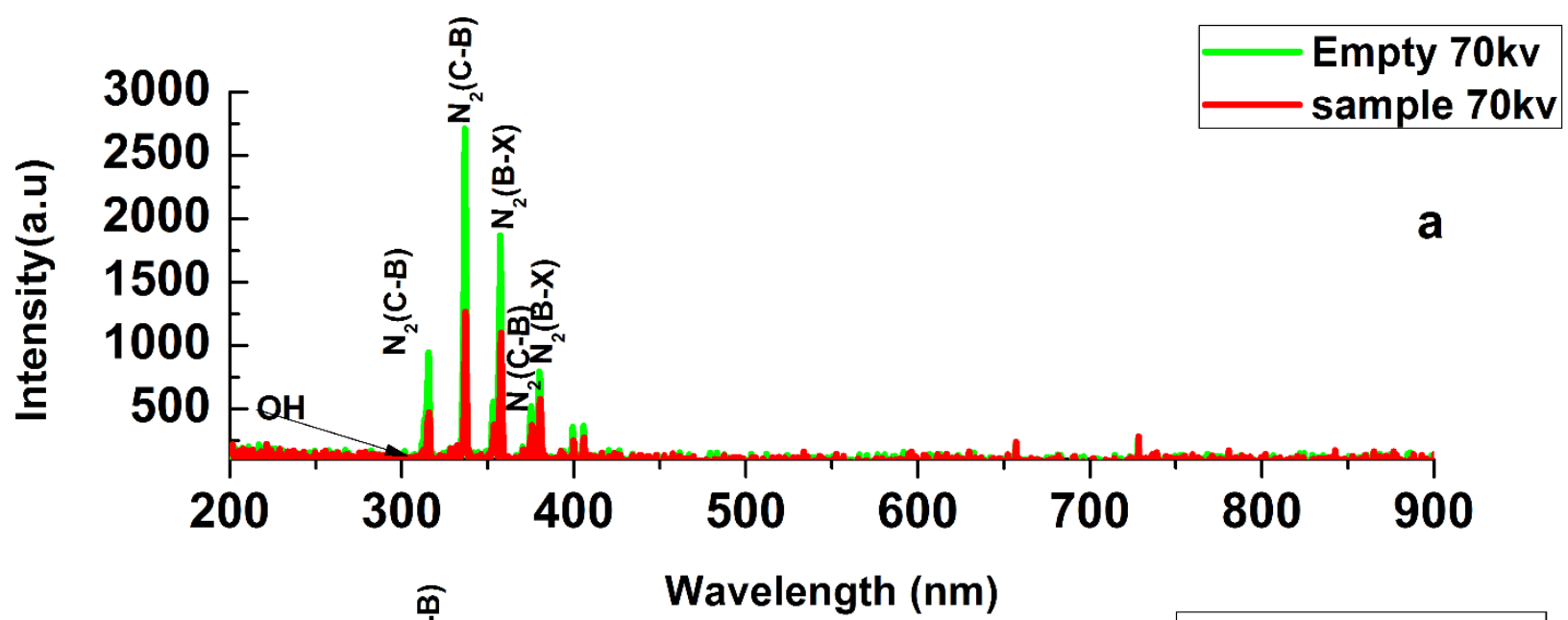

Fig.4.Typical Optical Emission Spectrum (OES) of the dielectric barrier discharge in air. 

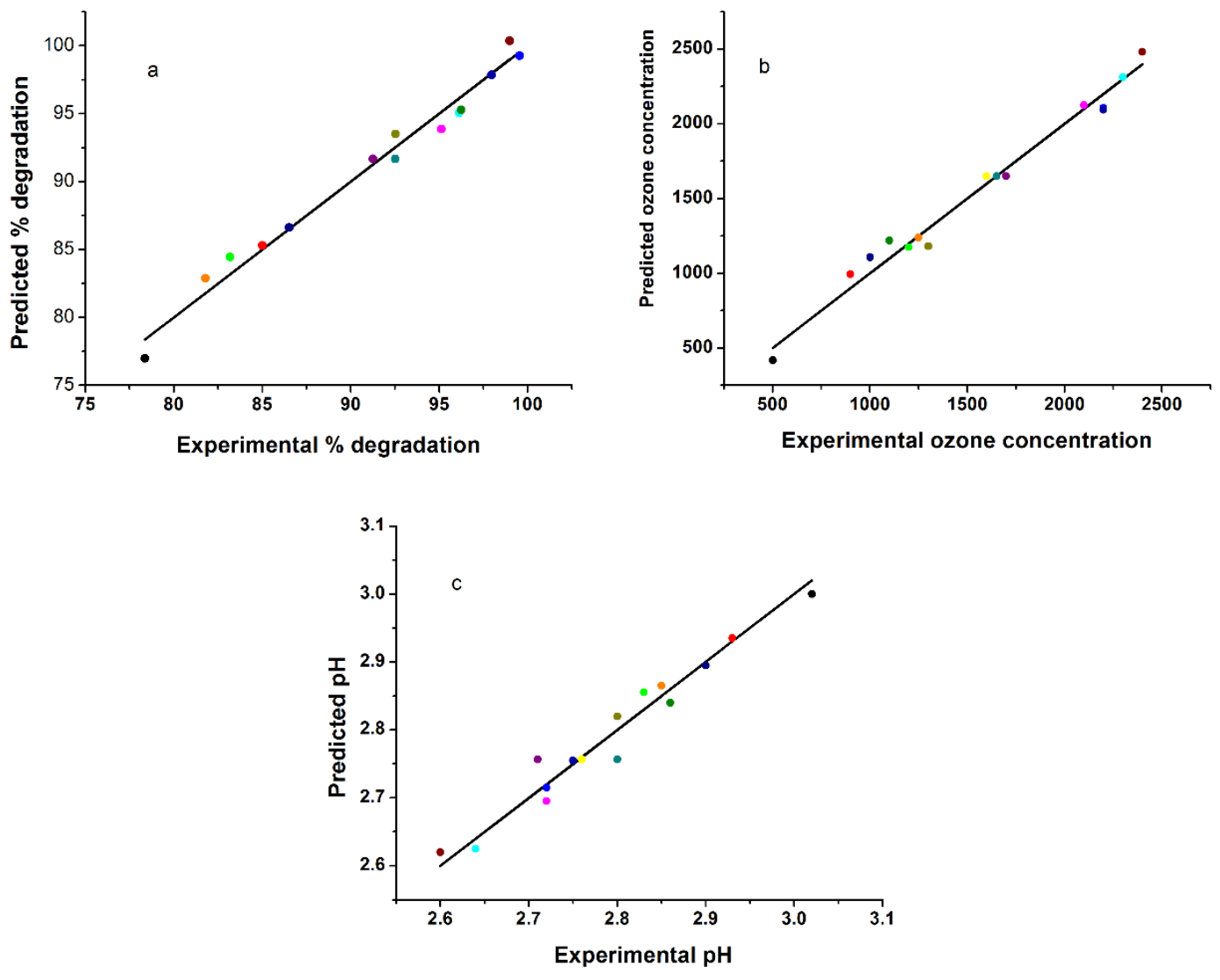

Fig.5. Correlation between predicted and experimental values for each of the degradation parameters studied a) $\%$ degradation b) ozone concentration c) $\mathrm{pH}$ 

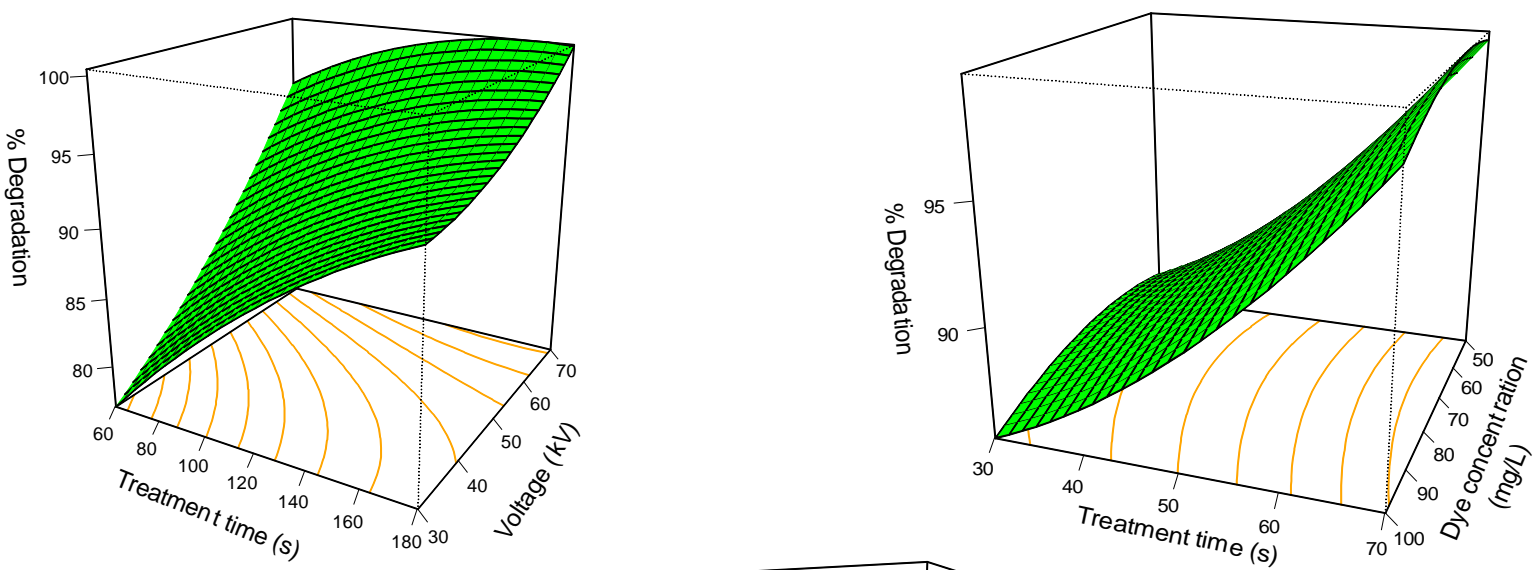

a

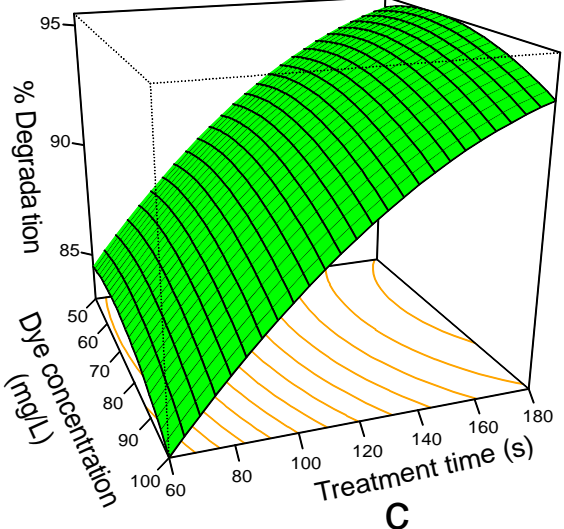

b 


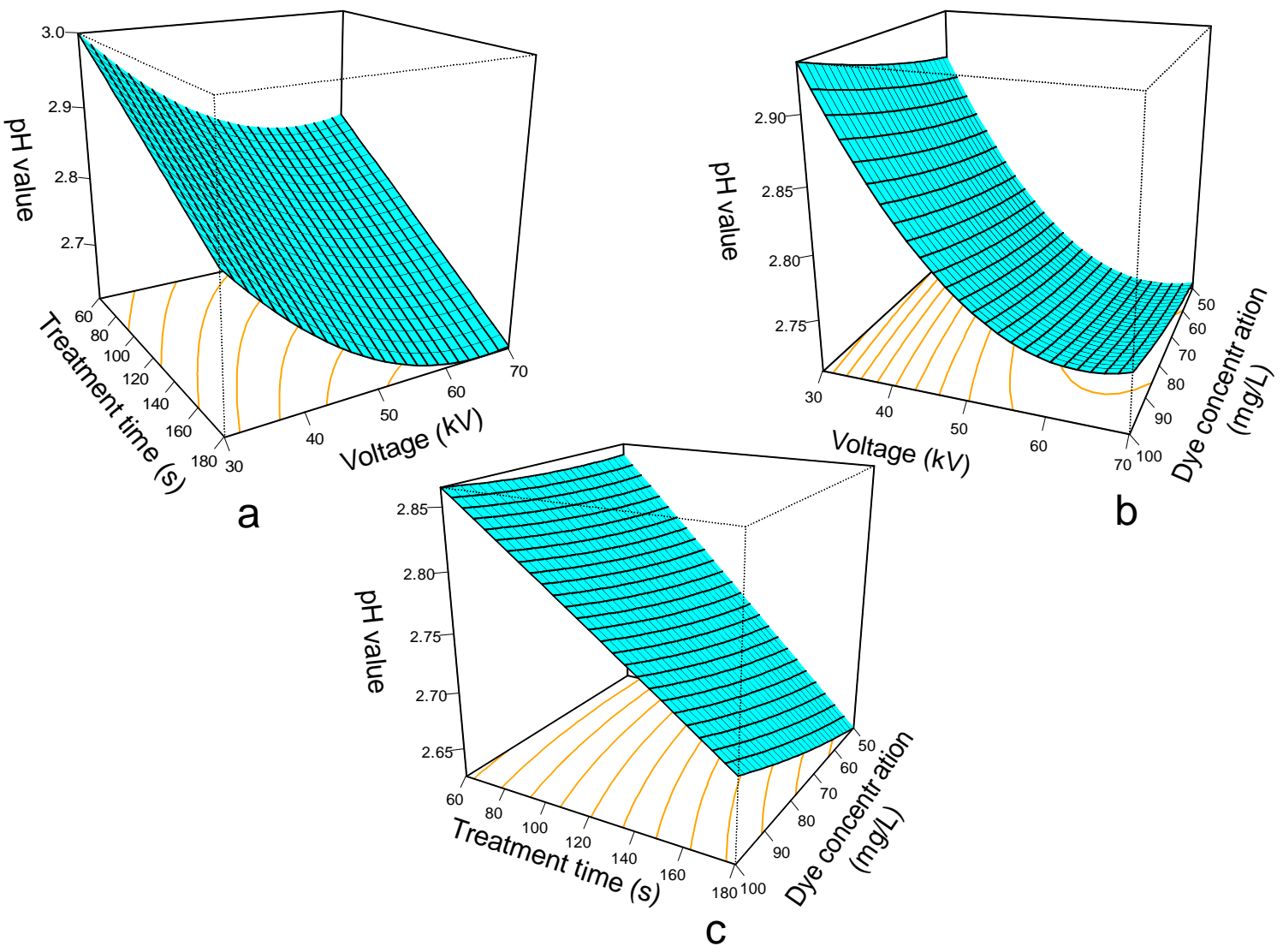

Fig.7. Surface plots for $\mathrm{pH}$ value 


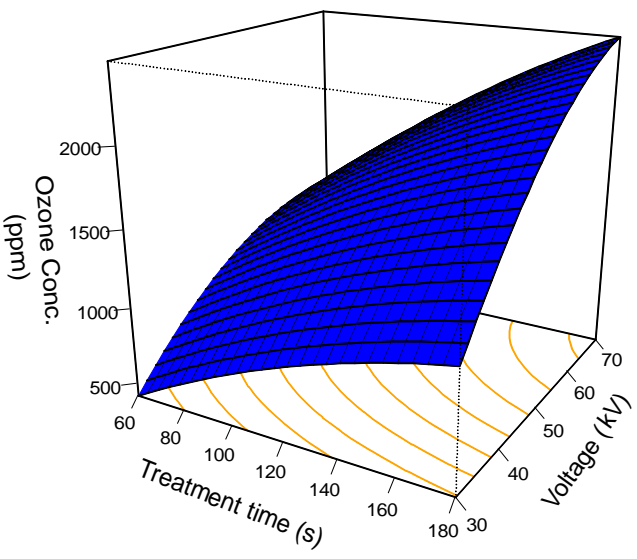

a

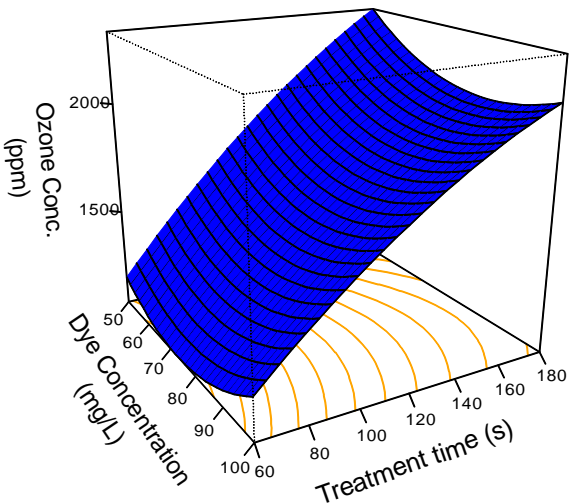

C

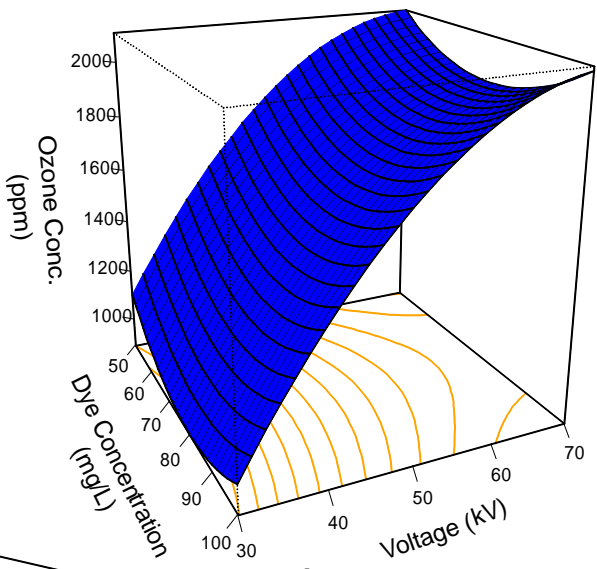

b

Fig.8. Surface plots for ozone concentration 
412 Tables

413 Table 1

414 Independent factors and their coded levels

416 Table 2

417 The 3-factor Box Behnken design matrix.

\begin{tabular}{llllll}
\hline $\begin{array}{l}\text { Independent } \\
\text { factors }\end{array}$ & Symbol & \multicolumn{3}{c}{ Coded levels } \\
\hline & Coded & Uncoded & -1 & 0 & +1 \\
Voltage $(\mathrm{kV})$ & $\mathrm{X}_{1}$ & $\mathrm{X}_{1}$ & 30 & 50 & 70 \\
Time $(\mathrm{Sec})$ & $\mathrm{X}_{2}$ & $\mathrm{X}_{2}$ & 60 & 120 & 180 \\
Dye & $\mathrm{X}_{3}$ & $\mathrm{X}_{3}$ & 50 & 75 & 100 \\
Concentration(mg/L) & & & & & \\
\hline
\end{tabular}

\begin{tabular}{lll}
\hline Experiment & Variables (coded level) & Variables (actual level)
\end{tabular}

\begin{tabular}{|c|c|c|c|c|c|c|}
\hline & $\begin{array}{c}\text { Voltage, } \\
\mathrm{X}_{1}\end{array}$ & $\begin{array}{c}\text { Treatment } \\
\text { time, } X_{2}\end{array}$ & $\begin{array}{c}\text { Dye } \\
\text { conc., } \\
\mathrm{X}_{3} \\
\end{array}$ & $\begin{array}{c}\text { Voltage, } x_{1} \\
(\mathrm{kV})\end{array}$ & $\begin{array}{c}\text { Treatment } \\
\text { time, } \mathrm{x}_{2} \\
(\mathrm{~s})\end{array}$ & $\begin{array}{c}\text { Dye } \\
\text { conc., } x_{3} \\
\text { (mg/L) }\end{array}$ \\
\hline 1 & -1 & -1 & 0 & 30 & 60 & 75 \\
\hline 2 & -1 & 0 & +1 & 30 & 120 & 100 \\
\hline 3 & 0 & -1 & -1 & 50 & 60 & 50 \\
\hline 4 & +1 & 0 & -1 & 70 & 120 & 50 \\
\hline 5 & 0 & +1 & -1 & 50 & 180 & 50 \\
\hline 6 & 0 & +1 & +1 & 50 & 180 & 100 \\
\hline 7 & 0 & 0 & 0 & 50 & 120 & 75 \\
\hline 8 & -1 & +1 & 0 & 30 & 180 & 75 \\
\hline 9 & -1 & 0 & -1 & 30 & 120 & 50 \\
\hline 10 & 0 & 0 & 0 & 50 & 120 & 75 \\
\hline 11 & +1 & +1 & 0 & 70 & 180 & 75 \\
\hline 12 & +1 & -1 & 0 & 70 & 60 & 75 \\
\hline 13 & 0 & 0 & 0 & 50 & 120 & 75 \\
\hline 14 & +1 & 0 & +1 & 70 & 120 & 100 \\
\hline 15 & 0 & -1 & +1 & 50 & 60 & 100 \\
\hline
\end{tabular}

419

420 
421 Table 3

422 Response functions for the testing of atmospheric air plasma treated dye mixture

\begin{tabular}{cccc}
\hline Experiment no. & \multicolumn{3}{c}{ Response functions } \\
\cline { 2 - 4 } & \multicolumn{3}{c}{ Experimental values } \\
\cline { 2 - 4 } \% degradation $(\%)$ & pH value & Ozone concentration $(\mathrm{ppm})$ \\
\hline 1 & 78.365 & 3.02 & 500 \\
3 & 85.0123 & 2.93 & 900 \\
4 & 83.172 & 2.83 & 1200 \\
5 & 99.5426 & 2.72 & 2200 \\
6 & 96.125 & 2.64 & 2300 \\
7 & 95.1253 & 2.72 & 2100 \\
8 & 91.256 & 2.76 & 1600 \\
9 & 92.523 & 2.8 & 1300 \\
10 & 86.523 & 2.9 & 1000 \\
11 & 91.253 & 2.71 & 1700 \\
12 & 98.992 & 2.6 & 2400 \\
13 & 96.243 & 2.86 & 1100 \\
14 & 92.513 & 2.8 & 1650 \\
15 & 97.956 & 2.75 & 2200 \\
\hline
\end{tabular}

423 Variables- $\mathrm{x}_{1}$ : Voltage, $\mathrm{x}_{2}$ : Treatment time, $\mathrm{x}_{3}$ : Dye concentration

424

425

426

6

47

48

49

427

$5 \odot$

51

52

428

54

55

56

57

58

59

60

61

62 
4

6

7 10

429 Table 4

430 Coefficient of polynomials and corresponding $t$ and $p$ values from the data of Box bhenken 431 design

\begin{tabular}{|c|c|c|c|c|c|c|}
\hline \multirow{2}{*}{$\begin{array}{l}\text { Source of } \\
\text { variation }\end{array}$} & \multicolumn{2}{|c|}{$\%$ degradation } & \multicolumn{2}{|c|}{$\mathrm{pH}$ value } & \multicolumn{2}{|c|}{ Ozone concentration } \\
\hline & $\begin{array}{c}\text { Coefficient } \\
\text { of polynomial }\end{array}$ & $\mathrm{t}$-value & $\begin{array}{c}\text { Coefficient } \\
\text { of polynomial }\end{array}$ & t-value & $\begin{array}{l}\text { Coefficient } \\
\text { of polynomial }\end{array}$ & t-value \\
\hline Constant & 91.674 & $100.626 * *$ & 2.757 & $123.557 * *$ & 1650.000 & $21.527 * *$ \\
\hline
\end{tabular}

\begin{tabular}{llllllc}
$\mathrm{x}_{1}$ & 6.289 & $11.272^{* * *}$ & -0.090 & $-6.587^{* *}$ & 525.000 & $11.185^{* * *}$ \\
$\mathrm{x}_{2}$ & 5.399 & $9.679^{* * *}$ & -0.100 & $-7.319^{* * *}$ & 506.250 & $10.786^{* * *}$ \\
$\mathrm{x}_{3}$ & -0.685 & $-1.229^{\mathrm{NS}}$ & 0.020 & $1.464^{\mathrm{NS}}$ & -31.250 & $-0.666^{\mathrm{NS}}$ \\
\hline
\end{tabular}

\begin{tabular}{ccccccc}
$\mathrm{x}_{1}{ }^{2}$ & 1.531 & $1.865^{\mathrm{NS}}$ & 0.064 & $3.191^{*}$ & -231.250 & $-3.347^{*}$ \\
$\mathrm{x}_{2}{ }^{2}$ & -1.674 & $-2.039^{\mathrm{NS}}$ & $-0.083 \times 10^{-2}$ & $-0.042^{\mathrm{NS}}$ & -93.750 & $-1.357^{\mathrm{NS}}$ \\
$\mathrm{x}_{3}{ }^{2}$ & -0.947 & $-1.153^{\mathrm{NS}}$ & 0.004 & $0.207^{\mathrm{NS}}$ & 156.250 & $2.262^{\mathrm{NS}}$ \\
\hline
\end{tabular}

\begin{tabular}{ccccccc}
$\mathrm{x}_{1} \mathrm{X}_{2}$ & -2.852 & $-3.615^{*}$ & -0.01 & $-0.518^{\mathrm{NS}}$ & 125.000 & $1.883^{\mathrm{NS}}$ \\
$\mathrm{x}_{1} \mathrm{X}_{3}$ & -0.019 & $-0.024^{\mathrm{NS}}$ & $-1.180 \times 10^{-16}$ & $0.000^{\mathrm{NS}}$ & 25.000 & $0.377^{\mathrm{NS}}$ \\
$\mathrm{x}_{2} \mathrm{X}_{3}$ & 0.096 & $0.122^{\mathrm{NS}}$ & 0.015 & $0.776^{\mathrm{NS}}$ & -62.500 & $-0.942^{\mathrm{NS}}$ \\
\hline $\mathrm{R}^{2}$ & \multicolumn{2}{c}{$0.98^{* * *}$} & \multicolumn{2}{c}{$0.96^{* *}$} & \multicolumn{2}{c}{$0.98^{* * *}$}
\end{tabular}

$432 \quad \mathrm{SE}=$ standard error; * Significant at $\mathrm{p} \leq 0.05 ; * *$ Significant at $\mathrm{p} \leq 0.01 ; * * *$ Significant at $\mathrm{p} \leq 0.001 ; * * * *$ Significant at $\mathrm{p} \leq 0.0001 ;$ $433{ }^{N S}$ not significant. 


\section{References}

Am Water Works Res F., Langlais B., Reckhow D. A. and Brink D. R. (1991). Ozone in water treatment: application and engineering. CRC press.

Amjad M., Salam Z., Facta M. and Ishaque K. (2012). A simple and effective method to estimate the model parameters of dielectric barrier discharge ozone chamber. Instrumentation and Measurement, IEEE Transactions on 61(6), 1676-83.

Anuar N., Mohd Adnan A. F., Saat N., Aziz N. and Mat Taha R. (2013). Optimization of extraction parameters by using response surface methodology, purification, and identification of anthocyanin pigments in Melastoma malabathricum fruit. The Scientific World Journal 2013.

Dojčinović B. P., Roglić G. M., Obradović B. M., Kuraica M. M., Kostić M. M., Nešić J. and Manojlović D. D. (2011). Decolorization of reactive textile dyes using water falling film dielectric barrier discharge. Journal of hazardous materials 192(2), 763-71.

Feng J., Zheng Z., Sun Y., Luan J., Wang Z., Wang L. and Feng J. (2008). Degradation of diuron in aqueous solution by dielectric barrier discharge. J Hazard Mater 154(1-3), 1081-9.

Grabowski L., Van Veldhuizen E., Pemen A. and Rutgers W. (2007). Breakdown of methylene blue and methyl orange by pulsed corona discharge. Plasma Sources Science and Technology 16(2), 226.

Heise M., Lierfeld T., Franken O. and Neff W. (2004). Single filament charge transfer and UV-emission properties of a cascaded dielectric barrier discharge (CDBD) set-up. Plasma Sources Science and Technology 13(2), 351.

Huang F., Chen L., Wang H. and Yan Z. (2010). Analysis of the degradation mechanism of methylene blue by atmospheric pressure dielectric barrier discharge plasma. Chemical Engineering Journal 162(1), 250-6.

Jiang B., Zheng J., Lu X., Liu Q., Wu M., Yan Z., Qiu S., Xue Q., Wei Z. and Xiao H. (2013). Degradation of organic dye by pulsed discharge non-thermal plasma technology assisted with modified activated carbon fibers. Chemical Engineering Journal 215, 969-78.

Jiang B., Zheng J., Qiu S., Wu M., Zhang Q., Yan Z. and Xue Q. (2014). Review on electrical discharge plasma technology for wastewater remediation. Chemical Engineering Journal 236, 348-68.

Kasiri M. B., Modirshahla N. and Mansouri H. (2013). Decolorization of organic dye solution by ozonation; Optimization with response surface methodology. International Journal of Industrial Chemistry 4(1), 1-10.

Laux C., Spence T., Kruger C. and Zare R. (2003). Optical diagnostics of atmospheric pressure air plasmas. Plasma Sources Science and Technology 12(2), 125.

Machala Z., Janda M., Hensel K., Jedlovský I., Leštinská L., Foltin V., Martišovitš V. and Morvova M. (2007). Emission spectroscopy of atmospheric pressure plasmas for bio-medical and environmental applications. Journal of Molecular Spectroscopy 243(2), 194-201.

Maciejewska R., Ledakowicz S., Gebicka L. and Perkowski J. (2000). Ozonation kinetics of Reactive Blue 81 in aqueous solution. In: Proceedings of the International Specialized Symposium IOA, pp. 1-3.

Misra N. N., Keener K. M., Bourke P. and Cullen P. J. (2015). Generation of In-Package Cold Plasma and Efficacy Assessment Using Methylene Blue. Plasma Chemistry and Plasma Processing, 1-14.

Misra N. N., Pankaj S. K., Walsh T., O'Regan F., Bourke P. and Cullen P. J. (2014). In-package nonthermal plasma degradation of pesticides on fresh produce. J Hazard Mater 271(0), 33-40.

Moiseev T., Misra N. N., Patil S., Cullen P. J., Bourke P., Keener K. M. and Mosnier J. P. (2014). Postdischarge gas composition of a large-gap DBD in humid air by UV-Vis absorption spectroscopy. Plasma Sources Science and Technology 23(6), 065033.

Mok Y. S., Jo J.-O. and Whitehead J. C. (2008). Degradation of an azo dye Orange II using a gas phase dielectric barrier discharge reactor submerged in water. Chemical Engineering Journal 142(1), 56-64. 
Muthukumar M., Sargunamani D., Selvakumar N. and Venkata Rao J. (2004). Optimisation of ozone treatment for colour and COD removal of acid dye effluent using central composite design experiment. Dyes and Pigments 63(2), 127-34.

Oehmigen K., Hähnel M., Brandenburg R., Wilke C., Weltmann K. D. and von Woedtke T. (2010). The role of acidification for antimicrobial activity of atmospheric pressure plasma in liquids. Plasma Processes and Polymers 7(3-4), 250-7.

Patil S., Moiseev T., Misra N., Cullen P., Mosnier J., Keener K. and Bourke P. (2014). Influence of high voltage atmospheric cold plasma process parameters and role of relative humidity on inactivation of Bacillus atrophaeus spores inside a sealed package. Journal of Hospital Infection 88(3), 162-9.

Pearse R. W. B., Gaydon A. G., Pearse R. W. B. and Gaydon A. G. (1976). The identification of molecular spectra. Chapman and Hall London.

R Core Team R: A Language and Environment for Statistical Computing. http://www.R-project.org/.

Ravikumar K., Krishnan S., Ramalingam S. and Balu K. (2007). Optimization of process variables by the application of response surface methodology for dye removal using a novel adsorbent. Dyes and Pigments 72(1), 66-74.

Reddy P. M. K., Raju B. R., Karuppiah J., Reddy E. L. and Subrahmanyam C. (2013). Degradation and mineralization of methylene blue by dielectric barrier discharge non-thermal plasma reactor. Chemical Engineering Journal 217, 41-7.

Rohit Thirumdas C. S., MT Ajinkya, RR Deshmukh, US Annapure (2016). Influence of low pressure cold plasma on cooking and textural properties of brown rice. Innovative Food Science \& Emerging Technologies 37, 53-60.

Sarangapani C., Devi Y., Thirundas R., Annapure U. S. and Deshmukh R. R. (2015). Effect of low-pressure plasma on physico-chemical properties of parboiled rice. LWT-Food Science and Technology.

Sarangapani C., Misra N., Milosavljevic V., Bourke P., O'Regan F. and Cullen P. (2016a). Pesticide degradation in water using atmospheric air cold plasma. Journal of Water Process Engineering $\mathbf{9}$, 225-32.

Sarangapani C., Thirumdas R., Devi Y., Trimukhe A., Deshmukh R. R. and Annapure U. S. (2016b). Effect of low-pressure plasma on physico-chemical and functional properties of parboiled rice flour. LWT-Food Science and Technology 69, 482-9.

Thirumdas R., Sarangapani C. and Annapure U. (2015). Cold Plasma: A novel Non-Thermal Technology for Food Processing. Food Biophysics 10(1), 1-11.

Tizaoui C. and Grima N. (2011). Kinetics of the ozone oxidation of Reactive Orange 16 azo-dye in aqueous solution. Chemical engineering journal 173(2), 463-73.

Walsh J. L., Liu D. X., Iza F., Rong M. Z. and Kong M. G. (2010). Contrasting characteristics of submicrosecond pulsed atmospheric air and atmospheric pressure helium-oxygen glow discharges. Journal of Physics D: Applied Physics 43(3), 032001.

Wei L.-S., Yuan D.-K., Zhang Y.-F., Hu Z.-J. and Dong G.-P. (2014). Experimental and theoretical study of ozone generation in pulsed positive dielectric barrier discharge. Vacuum 104, 61-4.

Zuorro A., Fidaleo M. and Lavecchia R. (2013). Response surface methodology (RSM) analysis of photodegradation of sulfonated diazo dye Reactive Green 19 by UV/H2O2 process. Journal of Environmental Management 127(0), 28-35. 